University of Nebraska - Lincoln

DigitalCommons@University of Nebraska - Lincoln

Faculty Publications from the Harold W. Manter Laboratory of Parasitology

2000

\title{
A COX2 Molecular Phylogeny of the Peronosporomycetes
}

Deborah S.S. Hudspeth

Northern Illinos University

Steven A. Nadler

University of California - Davis, sanadler@ucdavis.edu

Michael E.S. Hudspeth

Northern Illinois University, mykes@niu.edu

Follow this and additional works at: https://digitalcommons.unl.edu/parasitologyfacpubs

Part of the Parasitology Commons

Hudspeth, Deborah S.S.; Nadler, Steven A.; and Hudspeth, Michael E.S., "A COX2 Molecular Phylogeny of the Peronosporomycetes" (2000). Faculty Publications from the Harold W. Manter Laboratory of Parasitology. 743.

https://digitalcommons.unl.edu/parasitologyfacpubs/743

This Article is brought to you for free and open access by the Parasitology, Harold W. Manter Laboratory of at DigitalCommons@University of Nebraska - Lincoln. It has been accepted for inclusion in Faculty Publications from the Harold W. Manter Laboratory of Parasitology by an authorized administrator of DigitalCommons@University of Nebraska - Lincoln. 


\section{A COX2 molecular phylogeny of the Peronosporomycetes}

Deborah S. S. Hudspeth

Department of Biological Sciences, Northern Illinois University, DeKalb, Illinois 60115

Steven A. Nadler

Department of Nematology, University of California, Davis, California 95616

Michael E. S. Hudspeth ${ }^{1}$

Department of Biological Sciences, Northern Illinois University, DeKalb, Illinois 60115

\begin{abstract}
The evolutionary history of the mitochondrial COX2 locus has been used to infer the phylogenetic relationships among 15 peronosporomycete and a hyphochytriomycete species. This molecular phylogenetic analysis at both the ordinal and generic levels provides strong evidence for the recognition of the Saprolegniomycetidae and the Peronosporomycetidae as natural groups, and for the monophyly of the Saprolegniales, Leptomitales and Pythiales. A three amino acid insertion/deletion event (indel) has been identified as a putative synapomorphy for the Saprolegniales. Parsimony mapping of 12 morphological and biochemical characters on the COX2 molecular phylogeny yields an hypothesis for peronosporomycete ancestral states and shared-derived features.

Key Words: Achlya, Aphanomyces, Apodachlya, cytochrome $c$ oxidase, Dictyuchus, Hyphochytrium, Lagenidium, Leptolegnia, Leptomitus, Oomycetes, Peronophythora, Peronosporomycetidae, Phytophthora, Plectospira, Pythiopsis, Pythium, Saprolegnia, Saprolegniomycetidae, Thraustotheca
\end{abstract}

\section{INTRODUCTION}

The Peronosporomycetes, traditionally referred to as oomycetes, are a class of fungus-like heterotrophs placed in the Kingdom Straminipila (for initial assemblage see Patterson 1989). The diversity of this Kingdom, whose sole synapomorphy is the appearance of tripartite tubular hairs (stramenopiles) at some point during the life cycle of its members, is

Accepted for publication January 13, 2000.

1 Email: mykes@niu.edu reflected by the inclusion of the autotrophic heterokont chromophytic algae (chlorophylls $a$ and $c$ ); the heterotrophic unicellular slopalinids (Proteromonas; Leipe et al 1996), bicosoecids (Cafeteria; Leipe et al 1994) and Developayella (Leipe et al 1996); and additional heterotrophic fungus-like heterokont groups such as the thraustochytrids, labyrinthulids and hyphochytriomycetes. Despite the apparent extreme diversity of its members the monophyly of the straminipiles has been strongly supported by several molecular systematic studies using data derived from small subunit r-RNA (SSURNA) and/or large subunit rRNA (e.g., Forster et al 1990, Leipe et al 1994, Van de Peer et al 1996, Van der Auwera et al 1995) and actin (Bhattacharya et al 1991, Bhattacharya and Ehlting 1995) gene sequences.

The Peronosporomycetes are a ubiquitous group of over 65 recognized genera (500-800 described species) with representatives found in most moist habitats (Dick 1990, 1995). The primary economic impact of the Peronosporomycetes results from the phytopathogenic genera, which include as hosts a wide variety of leguminous and cereal crops, and forest and rosaceous fruit trees. As the causative agents of downy mildews, white rusts, and a variety of root rots and late blights they are a significant detriment to agriculture. Similarly, infection of roe, fingerlings, or freshwater and marine crustaceans and molluscans is of increasing concern to the rapidly expanding field of aquaculture. Yet despite their economic impact, no formal cladistic analysis involving more than a few peronosporomycetes is available, and the evolutionary relationships among the diverse genera within the class remain unresolved.

Over the last $25 \mathrm{yr}$ the major taxa of the Peronosporomycetes have undergone significant revision. The most traditional organization placed the taxa in four major orders: the Saprolegniales (Dick 1973a), the Leptomitales (Dick 1973b), the Lagenidiales (Sparrow 1973), and the Peronosporales (Waterhouse 1973). Several major reassessments of peronosporomycete systematics followed (e.g., CavalierSmith 1981, 1986, 1987, Beakes 1987) with the most detailed reorganizations proposed by Dick et al (1984) and Dick (1990, 1995). In generating the most recent of these taxonomic revisions Dick (1995) has provided a testable set of relationships. Based pri- 
marily on overall similarities of morphological characters, three subclasses (Peronosporomycetidae, Saprolegniomycetidae, and Rhipidiomycetidae) were erected with requisite subdivision and redistribution of existing orders.

Given the paucity of morphological and biochemical data for inferring peronosporomycete relationships, molecular-based approaches are very promising for understanding peronosporomycete phylogeny. Unfortunately, published molecular phylogenetic studies have typically included only one to five genera, and were primarily intended to assess the relationships of peronosporomycetes to other major eukaryotic groups. One of those studies (Forster et al 1990) used three SSURNA sequences to represent the Peronosporomycetidae and Saprolegniomycetidae; these authors noted that the three sequences were very similar to each other and suggested that less conserved DNA sequences may be needed. Subsequently, Lee and Taylor (1992) inferred relationships among several Phytophthora species using more variable rDNA internal transcribed spacer sequences. Neither of these studies, however, was intended to infer a peronosporomycete phylogeny per se, nor has a formal cladistic analysis of this group been published to date. Based on these reports and other studies where SSURNA data were sometimes unable to resolve closely related taxa (e.g., Nadler and Hudspeth 1998), we examined alternative loci prior to initiating our molecular phylogenetic analysis of the Peronosporomycetes.

Several factors suggested that the use of mtDNA would be helpful in establishing a peronosporomycete phylogeny. Foremost among these were: the extensive physical (Hudspeth et al 1983, Klimczak and Prell 1984, McNabb et al 1987, McNabb and Klassen 1988, Shumard-Hudspeth and Hudspeth 1990) and genic (Shumard et al 1986, Shumard-Hudspeth and Hudspeth 1990, Hudspeth 1992, Hudspeth and Hudspeth 1996) characterizations of a wide variety of peronosporomycete genomes; the ability to highly purify peronosporomycete mtDNA to obtain primary sequence data (Hudspeth et al 1980, 1983); the encoding of a variety of respiratory complex subunits ranging from very highly conserved to poorly conserved polypeptides; and, most recently, the availability from the Fungal Mitochondrial Genome Project of a variety of complete gene maps and sequences (Paquin et al 1997) including the complete mtDNA gene map of the peronosporomycete Phytophthora infestans. Although widely used for other organisms prior use of mtDNA for phylogenetic analyses of the Peronosporomycetes had been limited. Sachay et al (1993) used COX 2 and COX1 deduced amino acid data from Phytophthora to infer a closer relationship with plant rather than eufungal mitochondrial polypeptides. More recently Paquin et al (1995) and Chesnick et al (1996) used $P$. infestans amino acid data (NDH5 and $N D H 4 L$ ) to infer a noneufungal straminipilous relationship for the Peronosporomycetes.

In this study we have constructed an hypothesis for the evolutionary history of the peronosporomycete mitochondrial locus (COX2) encoding subunit 2 (COII) of cytochrome $c$ oxidase. By extension, DNA and deduced amino acid sequence data from 15 peronosporomycete taxa and a hyphochytriomycete have been used to infer the phylogenetic relationships among peronosporomycete species. Specifically, we ask if there is molecular support for the recognition of the Saprolegniomycetidae and the Peronosporomycetidae as natural groups; and, whether there is support for the placement of the Leptomitales within the Saprolegniomycetidae as recently proposed (Dick 1995). The analyses presented here represent the first rigorous cladistic analysis of this economically important, but greatly understudied class of the Straminipila.

\section{MATERIALS AND METHODS}

Strains and media.-Straminipile taxa used in this study were obtained from the following sources (ATCC catalogue numbers in parentheses): Achlya ambisexualis E87 (11400), A. Barksdale, New York Botanical Garden, New York, New York; Aphanomyces euteiches A466 S.E. Holub, University of Wisconsin, Madison, Wisconsin; Leptomitus lacteus (38076), J. Aronson, Arizona State University, Tempe, Arizona; Pythium ultimum 67-1 (32939), J.G. Hancock, University of California, Berkeley, California; Saprolegnia ferax (36051), I.B. Heath, York University, Toronto, Ontario, Canada. Dictyuchus sterilis (44891), Hyphochytrium catenoides (18719), Lagenidium yiganteum (36492), Leptolegnia caudata (48818), Peronophythora litchii (28739), Plectospira myriandra (64139), Pythiopsis cymosa (26880), Thraustotheca clavata (34112) were all purchased directly from ATCC, Manassas, Virginia. Apodachlya pyrifera and Sapromyces elongatus DNAs were provided by G. Klassen, University of Manitoba, Manitoba, Canada (McNabb and Klassen 1988).

Cultures were routinely maintained on potato dextrose agar, cornmeal agar, or Emerson's YpSs agar (Difco Laboratories, Troy, Michigan). Mycelia for DNA isolation were typically propagated in $8-\mathrm{L}$ or 16-L aerated carboys of PYG broth (Griffin et al 1974) at ambient temperatures. $H y$ phochytrium catenoides was propagated in stationary 2 L PYG for DNA preparation.

Escherichia coli (JM83; F; ara, $\Delta($ lac-proAB), rpsL, F80dlacZDM15) containing plasmid clones was cultured in LB broth (Maniatis et al 1982) supplemented with $50 \mu \mathrm{g} /$ $\mathrm{mL}$ ampicillin. Stocks and clones were cryopreserved in $25 \%$ glycerol at $-70 \mathrm{C}$.

DNA techniques.-Total DNA was prepared from late logphase mycelia and the mtDNA purified according to the 
protocol of Shumard et al (1986). Purified mitochondrial DNAs were obtained (Hudspeth et al 1980) as the upper band in a $\mathrm{CsCl}$ gradient $(\rho=1.65 \mathrm{~g} / \mathrm{mL})$, containing 100 $\mu \mathrm{g} / \mathrm{mL}$ bis-benzimide (Hoechst 33258; Calbiochem, La Jolla, California). Plasmid DNAs were isolated by the alkaline lysis method of Birnboim and Doly (1979).

Cloning and PCR. COII-encoding EcoRI fragments of Leptomitus lacteus, Aphanomyces euteiches, and Saprolegnia ferax, were cloned into pUC18 and transformed into JM83 following established procedures (Maniatis et al 1982). The peronosporomycete forward (GGCAAATGGGTTTTCAAGATCC) and reverse (CCATGATTAATACCACAAATTTCACTAC) primers for COX2 amplification were designed from aligned complete COX2 sequences of Phytophthora megasperma (Sachay et al 1993), A. euteiches, L. lacteus, and $S$. ferax. PCR amplifications $(25 \mu \mathrm{L})$ were optimized empirically in reactions containing $300 \mathrm{ng}$ mtDNA, $3 \mathrm{~mm} \mathrm{MgCl}_{2}, 12.5 \mathrm{nmol}$ each primer, and 0.25 units Taq polymerase (Promega, Madison, Wisconsin) in the buffer supplied by the manufacturer. Reactions were performed using the following cycling conditions: $96 \mathrm{C}, 4$ min; $96 \mathrm{C}, 30 \mathrm{~s} ; 50 \mathrm{C}, 30 \mathrm{~s}$; $72 \mathrm{C}, 1 \mathrm{~min}$; repeated 24 times from step 2; $72 \mathrm{C}, 4 \mathrm{~min}$. The fragment size and specificity of each reaction was assessed by agarose gel electrophoresis.

PCR products were ligated into the pGEM-T vector (Promega, Madison, Wisconsin) according to the manufacturer's suggested guidelines and transformed into E. coli JM83 (Maniatis et al 1982). White colonies were screened for appropriately sized inserts from a small scraping of agar-grown cells following boiling and removal of cellular debris by centrifugation. A 7.5- $\mu \mathrm{L}$ aliquot of the supernatant was amplified by PCR using the original reverse primer and a forward directed internal primer (GGTAGTCAATGGTATTGG) deduced from the original four aligned peronosporomycete COX2 sequences. The sizes of predicted PCR products were confirmed by agarose gel electrophoresis.

Sequencing and molecular techniques. DNA sequences of PCR-derived clones were confirmed by the use of different clones for each strand. DNA sequences were determined using the $\Delta T a q$ Cycle Sequencing Kit with 7-deaza-dGTP termination mixes and $\left[\alpha^{-32} \mathrm{P}\right]$ dATP $(\mathrm{ICN}$, Costa Mesa, California) according to the manufacturer's suggested guidelines (Amersham Corp., Arlington Heights, Illinois). Adjustments were made in the annealing temperature of the labeling reactions based on the theoretical $T_{n}$ of each primer used, and again for the termination reaction based on the predicted $\mathrm{T}_{\mathrm{m}}$ of the extended primer. For example, with an initial primer $\mathrm{T}_{\mathrm{m}}$ of $60 \mathrm{C}$ the following sets of parameters were used: labeling at $95 \mathrm{C}, 20 \mathrm{~s} ; 55 \mathrm{C}, 20 \mathrm{~s}$; repeated 39 times, and termination at $96 \mathrm{C}, 45 \mathrm{~s} ; 64 \mathrm{C}, 20 \mathrm{~s} ; 72 \mathrm{C}, 1$ min; repeated 29 times. Ends of inserts were determined by use of pGEM-T specific primers of our own design (GGCCAGTGAATTGTAATACGACTC and GACACTATAGAATGCTCAAGCTATGC). DNA transfer hybridizations and radiolabeled gene probes were prepared as previously described (Shumard-Hudspeth and Hudspeth 1990).

Sequence data management and phylogenetic analysis. Sequencing data files were organized and maintained using the PCGENE program group (Intelligenetics Inc., Mountain View, California). Clustal V, based on the alignment algorithm developed by Higgins and Sharp (1989), was used for preliminary multiple alignments of both nucleotide and amino acid sequences (Higgins et al 1992). Final alignments were adjusted manually to ensure that codon alignments were maintained. For phylogenetic analysis each homologous sequence position was treated as a discrete character with four possible unordered states (G, A, T, or C). Gaps were treated as missing data. PAUP* (test version 4.0.0d63) was used to infer maximum parsimony trees from these character-state data. Gaps (one nine-nucleotide indel) were treated as missing data in initial analyses; however, the parsimony analyses were repeated with this indel recoded (indel present/absent as the alternative states) as a single character (Swofford 1993, Crandall and Fitzpatrick 1996). Heuristic parsimony searches (with tree-bisection-reconnection branch swapping) were performed using 1000 replicates of random stepwise addition of taxa. Reported values for consistency indices exclude uniformative characters. Bootstrap resampling (2000 replicates) was used to estimate the relative reliability of inferred monophyletic groups. PHYLIP (version 3.3, Felsenstein 1993) was used for the maximum-likelihood analyses. Program options that were invoked are noted in the text where appropriate.

The nucleotide sequence data presented in this work have been deposited in GenBank as AF086687-AF086701 as a phylogenetic data set. Accession numbers for published sequences used to determine outgroups are as follows: Cyanidium Z48930, Prototheca U02970, Chondrus Z47547, Marchantia M68929, Allomyces U41288, Schizosaccharomyces X54421, Neurospora K00825, and Aspergillus X15441. Alignments and trees have been deposited in TreeBASE as S446 and M657.

\section{RESULTS}

The peronosporomycete $\mathrm{COX} 2$ locus.-In order to develop a molecular phylogenetic hypothesis for the Peronosporomycetes, we characterized the $C O X 2$ locus of representative genera. Purified mtDNAs from A. euteiches, L. lacteus, and $S$. ferax were restricted by $E c o R I$, and $C O X 2$-containing restriction fragments were identified by DNA transfer hybridization using a radiolabeled $C O X 2$ clone from $P$. megasperma (Sachay et al 1993). The appropriate $C O X 2$ fragments were then electroeluted, ligated into pUC19, and transformed into JM83. Recombinant plasmids were isolated and the sequence of the $C O X 2$ region determined. These sequences were then aligned with the comparable region from $P$. megasperma $695 \mathrm{~T}$ (Sachay et al 1993). This alignment, representing three major orders of peronosporomycetes, provided an initial estimate of peronosporomycete $C O X 2$ nucleotide sequence diversity, which enabled confident design of PCR primers for the efficient amplification of additional taxa. Our forward primer was positioned on a highly conserved N-terminal loop sequence region whereas the reverse primer exploited the presence of 
highly conserved or invariant residues in the copper binding region $\left(\mathrm{Cu}_{\mathrm{A}}\right)$ of the C-terminal globular domain (Iwata et al 1995). Use of these primers generated COX2 PCR products from an additional 11 peronosporomycete genera as well as the hyphochytriomycete representative $H$. catenoides. Of the 15 peronosporomycete taxa analyzed herein eight are type species.

Readily identifiable within the 15 deduced peronosporomycete and $H$. catenoides COII residues are those implicated in the $\mathrm{Cu}_{\mathrm{A}}$ binding region of COII (Iwata et al 1995, Tsukihara et al 1995). These residues as found in the Paracoccus denitrificans mature polypeptide (Iwata et al 1995) are Asp ${ }^{178}$, His ${ }^{181}$, $\mathrm{Cys}^{216}$, Glu${ }^{218}$, $\mathrm{Cys}^{220}, \mathrm{His}^{224}$, and $\mathrm{Met}^{227}$. The Asp ${ }^{183}$ and His ${ }^{186}$ of the processed peronosporomycete subunit (Sachay et al 1993) correspond to the Asp ${ }^{178}$ and $\mathrm{His}^{181}$ of $P$. denitrificans, and are conserved in all peronosporomycete and hyphochytriomycete sequences determined. All but one of the remaining conserved residues were included in the reverse PCR priming sequence and all are found in the four COX2 sequences for which the entire nucleotide sequence is available.

Alignment of the deduced COII amino acid sequences of the peronosporomycetes, hyphochytriomycete, and two algal outgroups identified a threecodon indel (insertion/deletion event). This deduced tripeptide sequence, which is predicted to lie within the mitochondrial intermembrane space (Holm et al 1987), is notably absent in all members of the Saprolegniales. It is, however, present as a potentially useful diagnostic feature within the Leptomitales (Saprolegniomycetidae) as -Tyr-Thr-Asp-, and within both the Peronosporales and the Rhipidiales (Peronosporomycetidae) as -Leu-Glu-Phe/Tyr-. The $H$. catenoides sequence is uniquely -Gln-Thr-Lys-

Codon usage for the 15 examined peronosporomycete COX2 loci (TABLE I) is governed by the expected $\mathrm{A} / \mathrm{T}$ third position bias previously reported for the Phytophthora mitochondrial genome (Sachay et al 1993, Paquin et al 1997) as well as for a variety of other peronosporomycete genera (Hudspeth and Hudspeth 1996). In two of the three six-fold degenerate codon families (Leu and Arg) a first and third position $\mathrm{A}$ or $\mathrm{T}$ is preferred with neither the $\mathrm{Leu}_{\mathrm{CTC}}$ and $\mathrm{Leu}_{\mathrm{CTG}}$ nor the $\mathrm{Arg}_{\mathrm{CGC}}$ codons used. Similarly, neither the $\operatorname{Ser}_{\mathrm{TCC}}$ nor the $\mathrm{Cys}_{\mathrm{TGC}}$ codons are employed in this region of COX2. Within the Thr codon family $\mathrm{Thr}_{\mathrm{ACC}}$ is used twice as frequently by the Saprolegniales s. s. (Achlya, Thraustotheca, Saprolegnia, Dictyuchus, and Pythiopsis) than by any other group. This same group also shows a stronger preference for $\mathrm{Arg}_{\mathrm{CGT}}$ versus other groups. In the Gly family $\mathrm{Gly}_{\mathrm{GGA}}$ is used three times more frequently within the Sap- rolegniales s. 1. (Aphanomyces, Leptolegnia, and Plectospira) than by any other group.

Outgroup selection.-In the absence of any prior COX2 phylogenetic analyses that included straminopile genera we considered a variety of potential outgroups for our study. It was determined from both the morphological literature (Dick 1990) and SSURNA analyses (Cavalier-Smith 1993, Van der Auwera et al 1995) that the hyphochytriomycetes are basal to the Peronosporomycetes, and that the rhodophyte (Cyanidium) and chlorophyte (Prototheca) representatives would be more distantly related. Previous SSURNA analyses using chrysophytes (Gunderson et al 1987), diatoms (Forster et al 1990), fucophytes (Bhattacharya and Stickel 1994), and hyphochytriomycetes (Van der Auwera et al 1995) had consistently placed these taxa in a position basal to the Peronosporomycetes. Similarly, the analysis of 150 eukaryotic SSURNA sequences (Cavalier-Smith 1993) included the Peronosporomycetes as part of the Heterokonta, a clade also including chrysophytes, diatoms, and fucophytes. To insure an appropriate outgroup choice, taxa previously included in peronosporomycete studies [e.g., plants and the more distantly related eufungi (Sachay et al 1993)] were included in a maximum parsimony (MP) analysis of COII sequences. Deduced COII sequences from several of these candidates were aligned with the deduced amino acid sequences from the 15 peronosporomycetes and $\mathrm{Hy}$ phochytrium catenoides (this study). Amino acid sequences from four ascomycetes, one chytridiomycete, two rhodophytes, one chlorophyte, and one bryophyte were subsequently aligned and the entire data set of 24 taxa analyzed by maximum parsimony. The strict consensus of the 21 most parsimonious trees found in a heuristic parsimony search (FIG. 1) clearly supported that the hyphochytriomycetes, rhodophytes, and chlorophytes were valid outgroup choices as inferred from COII sequences. Thus, Hyphochytrium catenoides, Cyanidium caldarium, and Prototheca wickerhamii were included as outgroups in all our analyses. The rhodophyte Chondrus crispus was excluded because it uses a nonstandard genetic code, which complicates amino acid based parsimony analysis.

Amino acid analysis.-Deduced amino acid sequences of 14 peronosporomycete genera and $H$. catenoides (this study) were aligned with data from $P$. megasper$m a$ (Sachay et al 1993), C. caldarium (GenBank Z48930), and $P$. wickerhamii (Wolff et al 1994) for amino acid analysis. One hundred fourteen of the 193 sites in the final alignment varied and, of these, 81 were phylogenetically informative in MP analysis. MP analysis of the amino acid data set (gaps treated as missing data) using a heuristic search strategy 
TABLE I. Codon usage

\begin{tabular}{|c|c|c|c|c|c|c|c|c|c|c|c|c|c|c|c|c|c|}
\hline & & A & B & $\mathrm{C}$ & D & $\mathrm{E}$ & $\mathrm{F}$ & G & & & A & B & C & D & $\mathrm{E}$ & $\mathbf{F}$ & G \\
\hline UUU & $\mathrm{F}$ & 177 & 90 & 92 & 95 & 79 & 91 & 90 & $\mathrm{UCU}$ & $\mathrm{S}$ & 61 & 34 & 36 & 47 & 45 & 20 & 33 \\
\hline UUC & $\mathrm{F}$ & 19 & 10 & 8 & 5 & 21 & 9 & 10 & UCC & $S$ & 0 & - & - & - & - & - & - \\
\hline UUA & $\mathrm{L}$ & 251 & 91 & 93 & 91 & 91 & 91 & 100 & UCA & $\mathrm{S}$ & 56 & 32 & 27 & 20 & 22 & 48 & 34 \\
\hline UUG & $\mathbf{L}$ & 6 & 2 & - & 4 & 9 & - & - & UCG & $\mathrm{S}$ & 2 & 1 & - & 3 & - & 2 & - \\
\hline CUU & $\mathrm{L}$ & 15 & 6 & 6 & 4 & - & 8 & - & $\mathrm{CCU}$ & $\mathrm{P}$ & 67 & 58 & 66 & 75 & 58 & 41 & 67 \\
\hline CUC & $\mathrm{L}$ & 0 & - & - & - & - & - & - & CCC & $\mathrm{P}$ & 5 & 4 & 3 & - & 21 & 3 & - \\
\hline CUA & $\mathrm{L}$ & 3 & 1 & 1 & 2 & - & 1 & - & CCA & $\mathrm{P}$ & 41 & 36 & 31 & 20 & 21 & 54 & 33 \\
\hline CUG & $\mathbf{L}$ & 0 & - & - & - & - & - & - & CCG & $\mathrm{P}$ & 2 & 2 & - & 5 & - & 2 & - \\
\hline AUU & I & 243 & 73 & 72 & 74 & 71 & 76 & 62 & $\mathrm{ACU}$ & $\mathrm{T}$ & 118 & 67 & 63 & 57 & 77 & 71 & 82 \\
\hline $\mathrm{AUC}$ & I & 8 & 2 & 4 & - & 4 & 2 & - & ACC & $\mathrm{T}$ & 15 & 9 & 16 & 7 & 8 & 2 & - \\
\hline AUA & I & 84 & 25 & 24 & 26 & 25 & 22 & 38 & ACA & $\mathrm{T}$ & 41 & 23 & 21 & 36 & 15 & 25 & 18 \\
\hline $\mathrm{AUG}$ & $\mathbf{M}$ & 57 & 100 & 100 & 100 & 100 & 100 & 100 & ACG & $\mathrm{T}$ & 1 & 1 & - & - & - & 2 & - \\
\hline GUU & $\mathrm{V}$ & 145 & 48 & 36 & 54 & 49 & 56 & 56 & GCU & A & 85 & 60 & 62 & 67 & 53 & 56 & 57 \\
\hline GUC & $\mathrm{V}$ & 2 & 1 & - & 1 & - & - & - & GCC & A & 4 & 3 & 2 & 7 & - & 3 & - \\
\hline GUA & $\mathrm{V}$ & 146 & 48 & 58 & 40 & 49 & 43 & 44 & GCA & A & 48 & 34 & 32 & 22 & 47 & 36 & 43 \\
\hline GUG & $\mathrm{V}$ & 11 & 3 & 6 & 5 & 2 & 1 & - & GCG & A & 5 & 4 & 4 & 4 & - & 5 & - \\
\hline UAU & $\mathrm{Y}$ & 91 & 94 & 97 & 100 & 100 & 80 & 88 & UGU & C & 29 & 100 & 100 & 100 & 100 & 100 & 100 \\
\hline UAC & $\mathrm{Y}$ & 6 & 6 & 3 & - & - & 20 & 12 & UGC & $\mathrm{C}$ & 0 & - & - & - & - & - & - \\
\hline UAA & - & 0 & - & - & - & - & - & - & UGU & - & 0 & - & - & - & - & - & - \\
\hline UAG & - & 0 & - & - & - & - & - & - & UGG & W & 75 & 100 & 100 & 100 & 100 & 100 & 100 \\
\hline CAU & $\mathrm{H}$ & 70 & 91 & 92 & 81 & 100 & 90 & 100 & CGU & $\mathrm{R}$ & 29 & 32 & 54 & 22 & 25 & 33 & 27 \\
\hline CAC & $\mathrm{H}$ & 7 & 9 & 8 & 19 & - & 10 & - & CGC & $\mathrm{R}$ & 0 & - & - & - & - & - & - \\
\hline CAA & $Q$ & 46 & 98 & 80 & 100 & 100 & 100 & 100 & CGA & $\mathrm{R}$ & 6 & 7 & - & 6 & 8 & 4 & - \\
\hline CAG & $Q$ & 3 & 2 & 20 & - & - & - & - & CGG & $\mathrm{R}$ & 1 & 1 & 3 & - & - & - & - \\
\hline AAU & $\mathrm{N}$ & 89 & 90 & 89 & 92 & 100 & 88 & 83 & AGU & $\mathrm{S}$ & 48 & 27 & 33 & 23 & 22 & 24 & 33 \\
\hline AAC & $\mathrm{N}$ & 10 & 10 & 11 & 8 & - & 12 & 17 & AGC & $\mathrm{S}$ & 10 & 6 & 4 & 7 & 11 & 6 & - \\
\hline AAA & $\mathrm{K}$ & 85 & 98 & 97 & 94 & 100 & 100 & 100 & AGA & $\mathrm{R}$ & 53 & 59 & 43 & 72 & 67 & 59 & 83 \\
\hline AAG & $\mathrm{K}$ & 2 & 2 & 3 & 6 & - & - & - & AGG & $\mathrm{R}$ & 1 & 1 & - & - & - & 4 & - \\
\hline GAU & $\mathrm{D}$ & 179 & 96 & 92 & 97 & 96 & 100 & 100 & GGU & G & 94 & 76 & 85 & 48 & 75 & 88 & 75 \\
\hline GAC & D & 7 & 4 & 8 & 3 & 4 & - & - & GGC & G & 2 & 2 & 3 & 3 & - & - & - \\
\hline GAA & $\mathrm{E}$ & 134 & 93 & 91 & 90 & 95 & 95 & 100 & GGA & G & 22 & 18 & 10 & 41 & 13 & 9 & 25 \\
\hline GAG & $\mathrm{E}$ & 10 & 7 & 9 & 10 & 5 & 5 & - & GGG & G & 6 & 4 & 3 & 8 & 13 & 3 & - \\
\hline
\end{tabular}

$\mathrm{A}=$ Actual number of codons used.

$\mathrm{B}=\%$ of that codon used for all Peronosporomycetes.

$\mathrm{C}=\%$ of Saprolegniales s.s. (Saprolegnia, Achlya, Thraustotheca, Dictyuchus, Pythiopsis).

$\mathrm{D}=\%$ of Saprolegniales s.l. (including Aphanomyces, Plectospira, Leptolegnia).

$\mathrm{E}=\%$ of Leptomitales (Apodachlya, Leptomitus).

$\mathrm{F}=\%$ of Pythiales (Pythium, Phytophthora, Lagenidium, Peronophythora).

$\mathrm{G}=\%$ of Rhipidales (Sapromyces).

- = Codon not used.

$-=$ termination codons.

yielded six most-parsimonious trees, each 304 steps with a consistency index $(\mathrm{CI})$ of 0.718 . The minimum branch lengths supporting internal nodes of all six trees ranged from 1 to 22 synapomorphies. The only differences among the six trees involved the placement of Pythiopsis and Saprolegnia within the Saprolegniomycetidae clade. Analysis of the amino acid data with the indel recoded as one additional character yielded the same six trees by parsimony. Boot- strap resampling was performed to assess relative levels of support for monophyletic groups (FIG. 2). Most nodes are reliably supported (recovered in $70 \%$ or more of the replicates). Polytomies and nodes not supported by bootstrap are in some instances resolved by the nucleotide analysis. It is notable that the Leptomitales, although not resolved as a monophyletic group in the amino acid analysis, is included with other taxa of the subclass Saprolegniomycetidae 


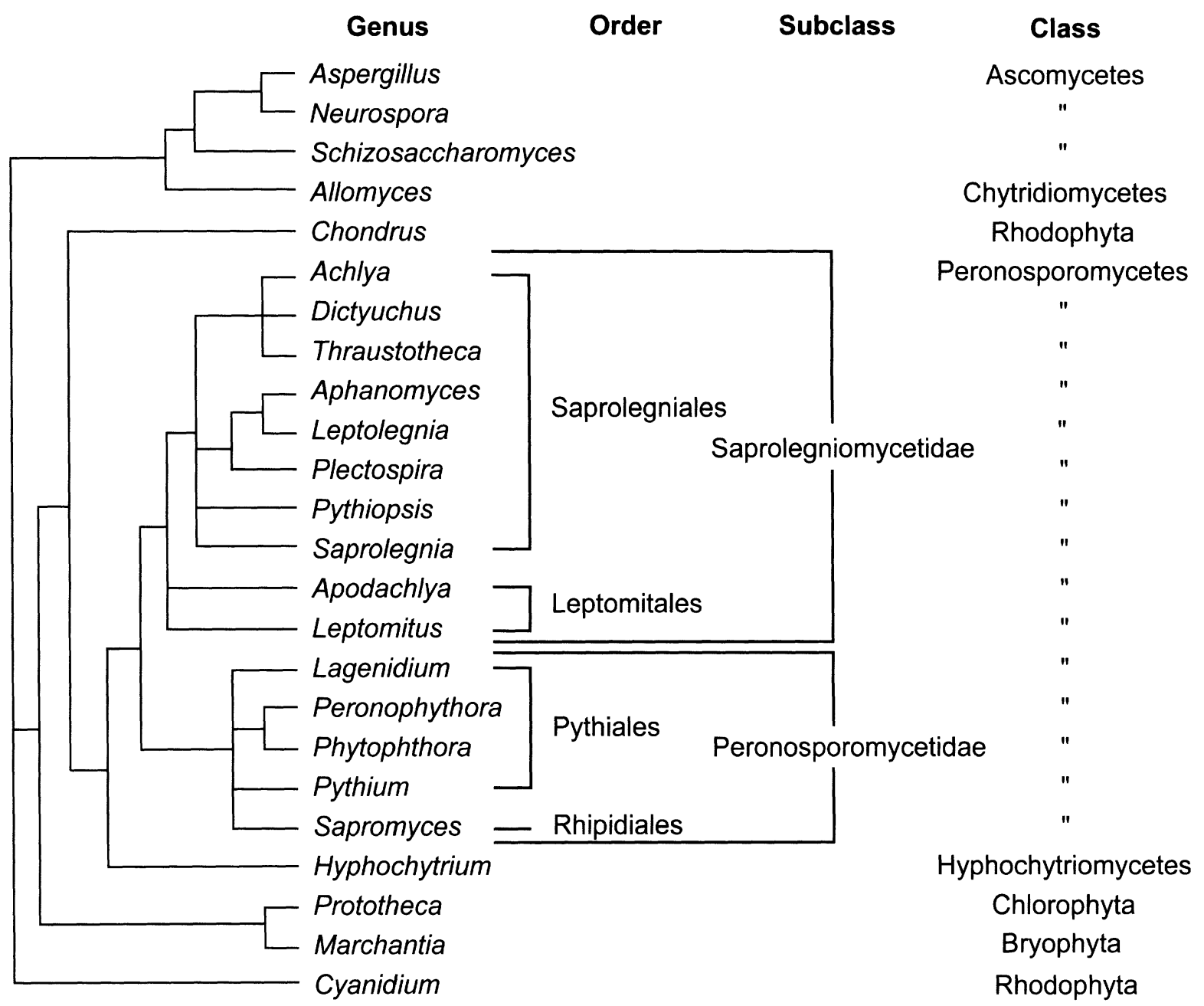

FIG. 1. Strict consensus of 21 amino acid data MP trees used for outgroup selection. Tree is midpoint rooted.

as recently suggested (Dick 1995), and not as a member of the Peronosporomycetidae as previously proposed (Dick 1990).

Nucleotide analysis.-An unambiguous alignment of the common nucleotide data set was obtained by Clustal V (Higgins et al 1992) with manual adjustment to maintain appropriate codon alignments. This data set consisted of 581 aligned sites exclusive of PGR primer regions. Of 344 variable nucleotide positions 250 were phylogenetically informative in MP analysis. Heuristic search of this data set (gaps treated as missing data) yielded two most parsimonious trees (not shown). These trees differed only in the placement of genera within the Pythiales clade. In one instance, Phytophthora and Peronophythora appeared as a clade and as a sister group to the clade consisting of Pythium and Lagenidium. In the alternative tree Pythium and Lagenidium formed a clade, but Peronophythora and Phytophthora did not. Conservatively recoding the indel as one character (pres- ence/absence of indel) and adding it to the data set yielded the same two trees.

The bootstrap MP tree (FIG. 3) provided evidence for monophyly of the two proposed subclasses (Dick 1990). The Saprolegniomycetidae included the sampled representatives of both the Saprolegniales and the Leptomitales in support of Dick's (1995) hypothesis. Similarly, the grouping of the clade containing Aphanomyces, Leptolegnia, and Plectospira with genera of the Saprolegniales s. s. lends strong support to the Saprolegniales s. 1. Bootstrap MP analysis also supports a clade consisting of both the Pythiales and Rhipidiales (subclass Peronosporomycetidae).

Of particular interest with respect to the parsimony tree was the unusual transition/transversion (Ts/Tv) ratio evident from the analysis. The minima/maxima of 272-331 transitions versus 627-686 transversions required by the $C O X 2$ data set yields a ratio of 0.5 . This phenomenon is most likely attributable to the high A-T content of peronosporomycete mitochondrial genomes which generate a codon usage strongly 


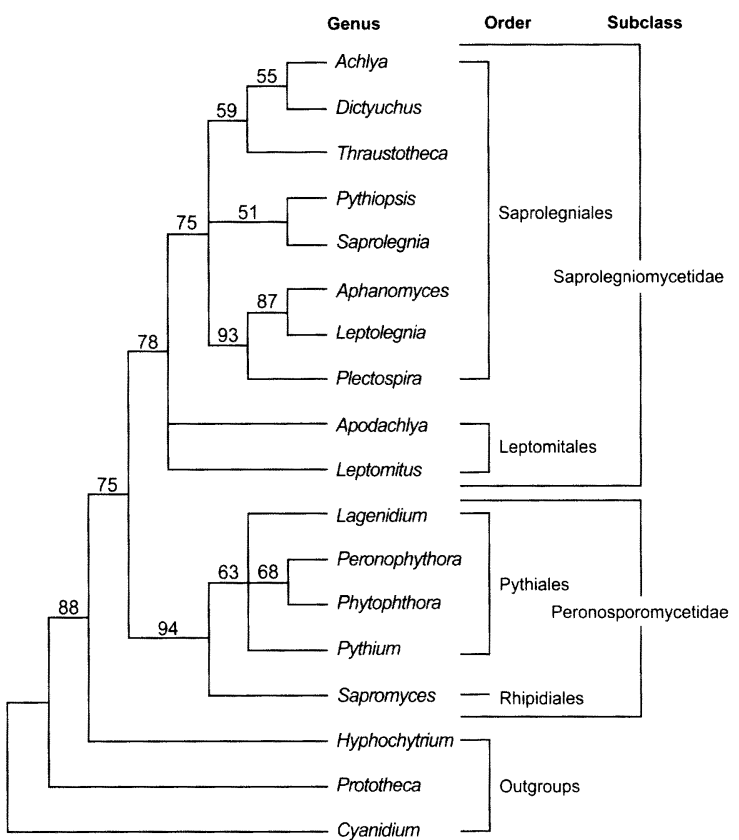

FIG. 2. MP fifty-percent majority-rule bootstrap consensus tree obtained from analysis of amino acid data set. Numbers represent bootstrap percentages of clades.

biased towards third position A's or T's (Sachay et al 1993). Thus, $A \rightarrow G$ and $T \rightarrow C$ transitions would be strongly selected against at third, and to a lesser extent first, codon positions.

Prompted by recent suggestions that maximum likelihood (ML) may frequently be a more accurate and robust method for inferring phylogeny (Huelsenbeck and Rannala 1997) ML analysis was performed using global rearrangement and jumble options of DNAml in the PHYLIP program package (Felsenstein 1993) which recovered the single tree shown in FIG. 4 (ln likelihood $=-5127.96820$ ).

\section{DISCUSSION}

A molecular phylogenetic hypothesis.-The consistent tree topologies generated by MP and ML combined with bootstrap values for nodes in both the amino acid and nucleotide MP trees lends support to this molecular hypothesis for the Peronosporomycetes. In essence, all tree topologies support recognizing the Peronosporomycetidae and the Saprolegniomycetidae as natural groups. In addition, both the Leptomitales and the Saprolegniales are included within the Saprolegniomycetidae as suggested by Dick (1995). The Saprolegniales in turn form two clades-the Saprolegniales s. s. consisting of Achlya, Thraustotheca, Dictyuchus, Pythiopsis, and Saprolegnia, and a sister clade containing Aphanomyces, Leptolegnia, and Plectospira. When combined these two clades constitute the more traditional Saprolegniales s. 1. (Dick 1973a).

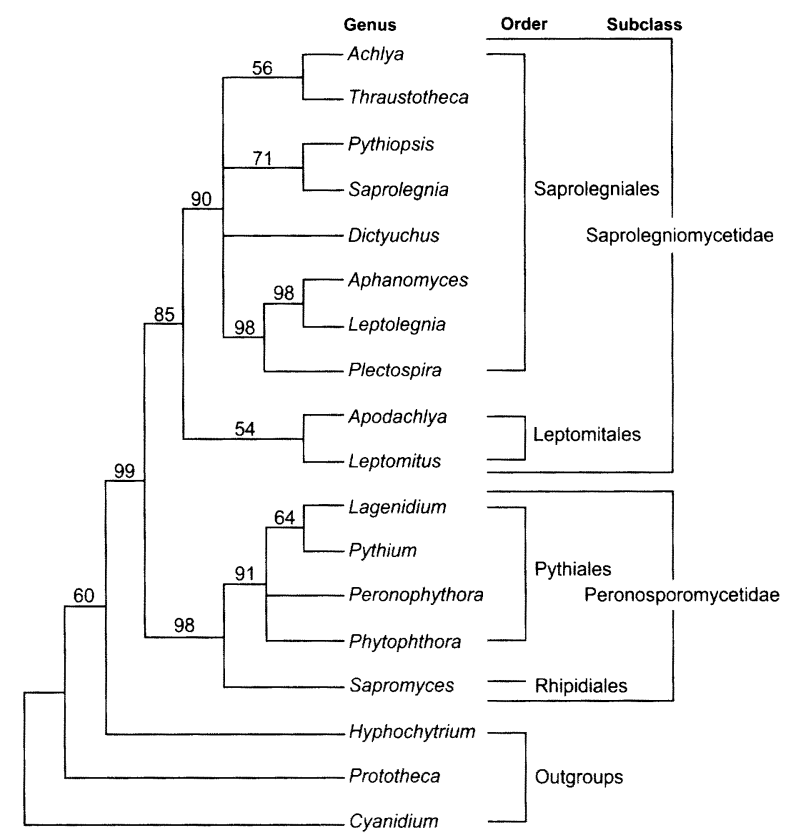

FIG. 3. MP fifty-percent majority-rule bootstrap consensus tree obtained from analysis of nucleotide data set. Numbers represent bootstrap percentages of clades.

Within the Saprolegniales s. s. the topology for Achlya, Thraustotheca, Dictyuchus, and Saprolegnia is identical to that inferred from ITS sequence data previously used in examining the evolution of zoosporangial emptying mechanisms for these genera (Daugherty et al 1998). In the Peronosporomycetidae all studied members of the Pythiales (Dick 1990) form a clade.

Two other molecular features discovered in this study also support these interpretations. Absence of the indel appears to be a diagnostic character for the Saprolegniales, whereas codon usage analysis of the COX2 locus for $\mathrm{Arg}_{\mathrm{CGT}}$, $\mathrm{Gly}_{\mathrm{GGA}}$, and $\mathrm{Thr}_{\mathrm{ACC}}$ also supports the separation of the Saprolegniales s. s.

Mapping of nonmolecular characters.-In an attempt to compare the COX2 molecular phylogeny with the nonphylogenetic classical interpretation of the morphological and biological characters of the Peronosporomycetes, 11 taxonomic characters and the amino acid gap as a character (see list in FIG. 4, only unambiguous character mappings are noted on the tree) were mapped using parsimony on the ML COX2 tree. Since no data for these characters exist outside of the Peronosporomycetes outgroup taxa could not be used to assist in the polarity determination. However, when considering the most parsimonious distribution of these character states on the ML tree (FIG. 4), ancestral (plesiomorphic) states and putative shared-derived features could be inferred in certain cases. These unambiguous map- 


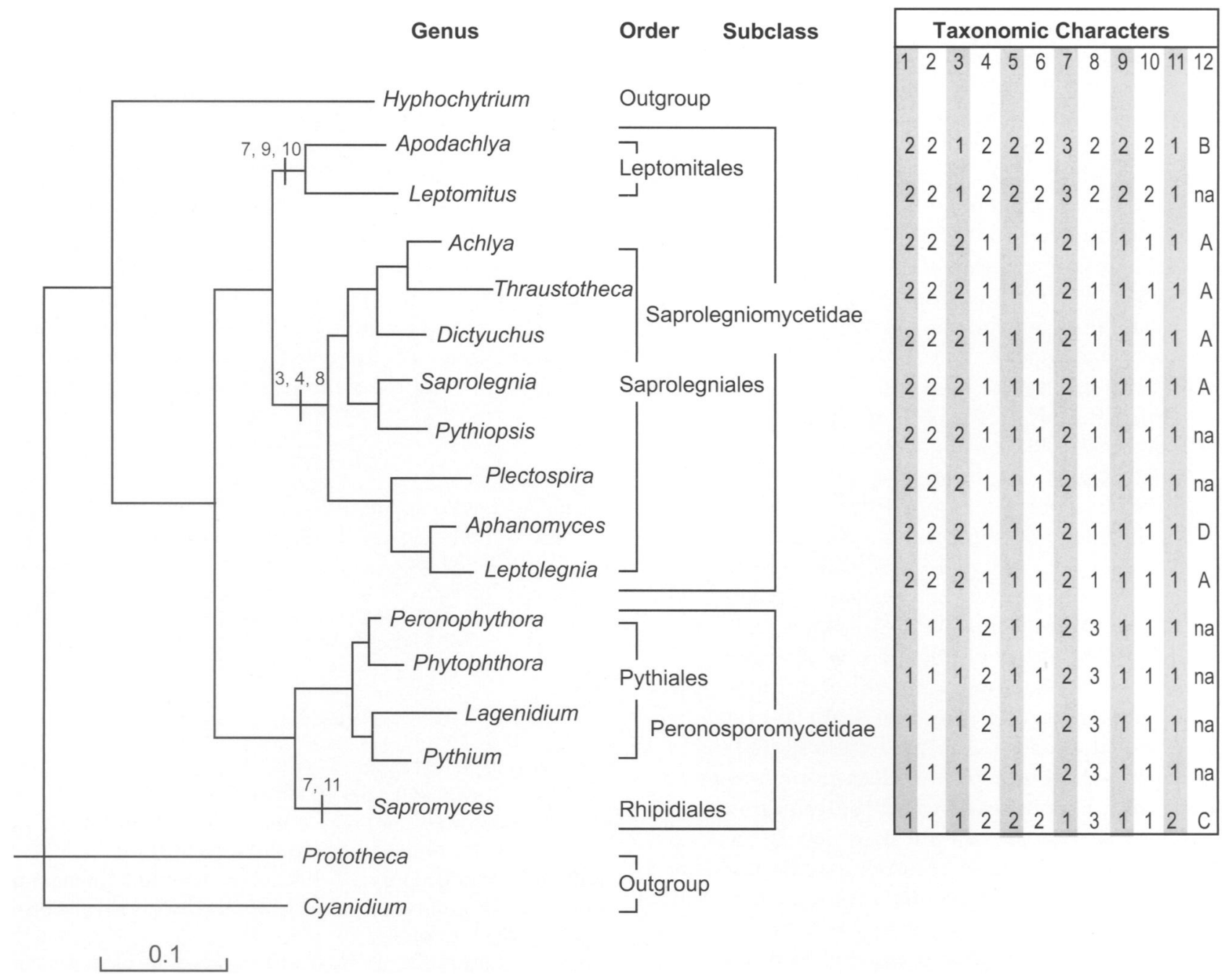

FIG. 4. ML COX2 tree with taxonomic characters listed. Numbers on the branches refer to characters unambiguously mapped by parsimony. Characters and character states are as follows; states in bold are apomorphic (derived) as inferred by mapping. 1. Lipid globules: numerous and centric only $=1$; centric, eccentric, subcentric or subeccentric, numerous or single $=2$ (Dick 1995); . Oosporogenesis: centripetal $=1$; centrifugal $=2$ (Dick 1995); 3 . Ooplast: solid and hyaline $=1$; fluid and granular $=2$ (Dick 1995); 4 . Use of $\mathrm{SO}_{4}^{-2}$ : unable to use $=1$; can use $=2$ (Reischer 1951a); 5 . Absolute requirement for organic nitrogen source: needs organic nitrogen $=2$; uses inorganic nitrogen $=1$ (Reischer 1951b); 6. Strict saprophytes $=2$; not strict saprophytes $=1$ (Dick 1990); 7. Oospore: elaborate exospore membrane $=1$; rarely ornamented intra-epispore membrane $=2$; gametic membrane $=3$ (Dick 1995); . Amino acid gap: 3 aa missing $=1 ; 3$ aa present $=2$, (this work); 9. Cellulin granules: present $=2$; none present $=1$ (Dick 1990); 10. Strongly oxidative $=2$; not notably oxidative $=1$ (Natvig 1982); 11. Fermentative $=2$; nonfermentative $=1$ (Dick 1990); 12. K-bodies: morphotypes as labelled in Powell and Blackwell (1995).

pings provide hypotheses for the evolutionary interpretation of certain classical peronosporomycete characteristics. For taxa where molecular data are likely to remain difficult to obtain, assessments of which traditional character states represent putative synapomorphies (versus shared ancestral states) are important for developing testable phylogenetic hypotheses.

As interpreted from the $C O X 2 \mathrm{ML}$ tree, a solid and hyaline ooplast and the ability to use $\mathrm{SO}_{4}{ }^{-2}$ as a sole source of sulfur appear to be ancestral (plesiomorph- ic) states retained by the Leptomitales, Pythiales, and Rhipidiales; by the tenets of cladistics, shared ancestral states are not informative about phylogenetic relationships. Other ancestral states inferred in this analysis include rarely ornamented intra-epispore membrane, absence of cellulin granules, and nonmarkedly oxidative metabolism. In contrast, a fluid and granular ooplast, and the loss of the ability to use $\mathrm{SO}_{4}{ }^{-2}$ as a sole source of sulfur are inferred to be shared-derived characters for the Saprolegniales (FIG. 4). Parsimony mapping suggests that three 
states are putative synapomorphies for the Leptomitales: a gametic membrane in the oospore, presence of cellulin granules, and strongly oxidative metabolism (FIG. 4). Fermentative metabolism and an elaborate exospore membrane appears to be derived within the Rhipidiales, however, additional taxa are needed to assess if members of this taxon are monophyletic. Character-state distributions for lipid globules and oosporogenesis are consistent with clades representing Peronosporomycetidae and Saprolegniomycetidae. However, ancestral states are equivocal for both characters, thus it is uncertain which clade(s) is supported by a shared-derived state in each case. Mapping of K-body morphotypes (Powell and Blackwell 1995) on the COX2 tree does not yield any unambiguous hypothesis regarding which states may be shared-derived features.

Considering only the presence or absence of the three amino acid indel, loss of these residues is a putative synapomorphy for the Saprolegniales (FIG. 4). With consideration of the presence and type of amino acids found in Hyphochytrium (the sister-taxon to the Peronosporomycetes in the molecular trees), amino acid states in Leptomitales (YTD), and Pythiales plus Rhipidiales (LEF/Y) are also shared-derived states. The distribution of the character mappings for strict saprophytic nutrition and the requirement for organic nitrogen are identical, which is consistent with the idea that these features may be correlated as a consequence of organismal ecology. However, for these latter two characters parsimony mapping yields equivocal reconstructions for ancestral lineages deep in the tree such that interpretation of the derived versus ancestral condition is not possible by this approach.

An heuristic search of the 12 taxonomic characters for the 15 oomycete taxa yields 5250 trees (maxtrees set to 10000 ) each with a length of 18 and a CI of 0.857 (excluding uninformative characters). Both the strict consensus and the $50 \%$ majority-rule consensus of these trees yield identical topologies (trees not shown). Characters in these analyses were treated as unordered states and the tree was midpoint rooted because these data were unavailable for the outgroup taxa. Since the indel character is derived from the molecular data set a separate heuristic search excluding it was also performed. The exclusion of the indel made no difference in either tree topology or the number of trees, but treelength was reduced to 16 and CI to 0.833. Although the consensus trees from these analyses were poorly resolved, it is notable that the Saprolegniales and Leptomitales were recovered as monophyletic groups.

This work has provided the first molecular phylogenetic analysis, at both the ordinal and generic level, of this economically important group of straminopiles. Monophyletic groups have been hypothesized at the ordinal level for the Saprolegniales, Leptomitales, and the Pythiales. However, additional representatives of the Rhipidiales will be required to assess monophyly for this order. Additional studies have already been initiated that involve the addition of more diverse taxa, and the inclusion of other genetic loci. It is anticipated that a more comprehensive molecular phylogeny for this group can contribute to an improved understanding of the Peronosporomycetes by providing an expanded evolutionary framework for interpreting their biological characteristics.

\section{ACKNOWLEDGMENTS}

This work was supported in part by Public Health Service grant GM51110 from the National Institutes of Health, grant DEB-9807937 from the National Science Foundation, and by the Plant Molecular Biology Center and the Department of Biological Sciences at Northern Illinois University.

\section{LITERATURE CITED}

Beakes GW. 1987. Oomycete phylogeny: Ultrastructural perspectives. In: Rayner ADM, Brasier CM, Moore D, eds. Evolutionary biology of the fungi. Cambridge: Cambridge University Press. p 405-421.

Bhattacharya D, Ehlting J. 1995. Actin coding regions: gene family evolution and use as a phylogenetic marker. Arch Protistenkd 145:155-164.

—_, Stickel SK. 1994. Sequence analysis of duplicated actin genes in Lagenidium giganteum and Pythium irregulare (Oomycota). J Mol Evol 39:56-61.

,-- , Sogin ML. 1991. Molecular phylogenetic analysis of actin genic regions from Achlya bisexualis (Oomycota) and Costaria costata (Chromophyta). J Mol Evol 33:525-536.

Birnboim HC, Doly J. 1979. A rapid alkaline extraction procedure for screening recombinant plasmid DNA. Nucl Acids Res 7:1513-1523.

Cavalier-Smith T. 1981. Eukaryote kingdoms: seven or nine? BioSystems 14:461-481.

1986. The kingdom Chromista: origin and systematics. In: Round FE, Chapman DJ, eds. Progress in phycological research. Vol. 4. Bristol, UK: Biopress. p 309347.

. 1987. The origin of fungi and pseudofungi. In: Rayner ADM, Brasier CM, Moore D, eds. Evolutionary biology of the fungi. Cambridge: Cambridge University Press. p 405-421.

- 1993. Kingdom Protozoa and its 18 phyla. Microbiol Rev 57:953-994.

Chesnick JM, Tuxbury K, Coleman A, Burger G, Lang BF. 1996. Utility of the mitochondrial nad $4 L$ gene for algal and protistan phylogenetic analysis. J Phycol 32:452456. 
Crandall KA, Fitzpatrick JF Jr. 1996. Crayfish molecular systematics: using a combination of procedures to estimate phylogeny. Syst Biol 45:1-26.

Daugherty J, Evans TM, Skillom T, Watson LE, Money NP. 1998. Evolution of spore release mechanisms in the Saprolegniaceae (Oomycetes): evidence from a phylogenetic analysis of internal transcribed spacer sequences. Fungal Genet Biol 24:354-363.

Dick MW. 1973a. Saprolegniales. In: Ainsworth GD, Sparrow FK, Sussman AS, eds. The fungi. An advanced treatise. Vol. IVB. New York: Academic Press. p 113-144.

—. 1973b. Leptomitales. In: Ainsworth GD, Sparrow FK, Sussman AS, eds. The fungi. An advanced treatise. Vol. IVB. New York: Academic Press. p 145-158.

- 1990. Phylum Oomycota. In: Margulis L, Corliss JO, Melkonian M, Chapman DJ, eds. Handbook of Protoctista. Boston: Jones and Bartlett Publishers. p 661-685.

-1995. Sexual reproduction in the Peronosporomycetes (chromistan fungi). Can J Bot 73(Suppl 1):S712-S724.

- Wong PTW, Clark G. 1984. The identity of the oomycete causing 'Kikuyu Yellows', with a reclassification of the downy mildews. Bot J Linn Soc 89:171-197.

Felsenstein J. 1993. PHYLIP (Phylogeny Inference Package) version 3.5c. Distributed by the Author. Seattle: University of Washington, Department of Genetics.

Forster H, Coffey MD, Elwood H, Sogin ML. 1990. Sequence analysis of the small subunit ribosomal RNAs of three zoosporic fungi and implications for fungal evolution. Mycologia 82:306-312.

Griffin DH, Timberlake WE, Cheney JC. 1974. Regulation of macromolecular synthesis, colony development, and specific growth rate of Achlya bisexualis during balanced growth. J Gen Microbiol 80:381-388.

Gunderson JH, Elwood H, Ingold A, Kindle K, Sogin ML. 1987. Phylogenetic relationships between chlorophytes, chrysophytes, and oomycetes. Proc Natl Acad Sci USA 84:5823-5827.

Higgins DG, Bleasby AJ, Fuchs R. 1992. CLUSTAL V: Improved software for multiple sequence alignment. Cabios 8:189-191.

— Sharp PM. 1989. Fast and sensitive multiple sequence alignments on a microcomputer. Cabios 5:151153.

Holm L, Saraste M, Wikstrom M. 1987. Structural models of the redox centres in cytochrome oxidase. EMBOJ 6 : 2819-2823.

Hudspeth MES. 1992. The fungal mitochondrial genomea broader perspective. In: Arora DK, Mukerji KG, Elander RP, eds. Handbook of applied mycology. Vol. 4. Biotechnology. New York: P. Marcel Dekker. p 213-241.

- Hudspeth DSS. 1996. Mitochondrial genomes of the zoosporic fungi. In: Dayal R, ed. Advances in zoosporic fungi. New Delhi: MD Publications. p 173-199.

— Shumard DS, Bradford CJR, Grossman LI. 1983. Organization of Achlya mtDNA: a population with two orientations and a large inverted repeat containing the rRNA genes. Proc Natl Acad Sci USA 80:142-146.

, $\longrightarrow$, Tatti KM, Grossman LI. 1980. Rapid purification of yeast mitochondrial DNA in high yield. Biochim Biophys Acta 610:221-228.
Huelsenbeck JP, Rannala B. 1997. Phylogenetic methods come of age: testing hypotheses in an evolutionary context. Science 276:227-231.

Iwata S, Ostermeier C, Ludwig B, Michel H. 1995. Structure at 2.8 A resolution of cytochrome $c$ oxidase from Paracoccus denitrificans. Nature 376:660-669.

Klimczak LJ, Prell HH. 1984. Isolation and characterization of mitochondrial DNA of the oomycetous fungus Phytophthora infestans. Curr Genet 8:323-326.

Lee SB, Taylor JW. 1992. Phylogeny of five fungus-like protoctistan Phytophthora species, inferred from the internal transcribed spacers of ribosomal RNA. Mol Biol Evol 9:636-653.

Leipe DD, Tong SM, Goggin CL, Slemenda SB, Pieniazek NJ, Sogin ML. 1996. 16S-like rDNA sequences from $D e-$ velopayella elegans, Labyrinthuloides haliotidis, and Proteromonas lacertae confirm that the stramenopiles are a primarily heterotrophic group. Eur J Protistol 32:449458.

- Wainwright PO, Gunderson JH, Porter D, Patterson DJ, Valois F, Himmerich S, Sogin ML. 1994. The stramenopiles from a molecular perspective: 16S-like rRNA from Labyrinthuloides minuta and Cafeteria roenbergensis. Phycologia 33:369-377.

Maniatis T, Fritsch EF, Sambrook J. 1982. Molecular cloning: a laboratory manual. Cold Spring Harbor, New York: Cold Spring Harbor Laboratory.

McNabb SA, Boyd DA, Belkhiri A, Dick MW, Klassen GR. 1987. An inverted repeat comprises more than threequarters of the mitochondrial genome in two species of Pythium. Curr Genet 12:205-208.

- Klassen GR. 1988. Uniformity of mitochondrial complexity in Oomycetes and the evolution of the inverted repeat. Exp Mycol 12:233-242.

Nadler SA, Hudspeth DSS. 1998. Ribosomal DNA phylogeny of the Ascaridoidea (Nemata: Secernentea): Implications for morphological evolution and classification. Mol Phylogenet Evol 10:221-236.

Natvig DO. 1982. Comparative biochemistry of oxygen toxicity in lactic acid-forming aquatic fungi. Arch Microbiol 132:107-114.

Paquin B, Laforest M-J, Forget L, Roewer I, Wang Z, Longcore J, Lang BF. 1997. The fungal mitochondrial genome project: evolution of fungal mitochondrial genomes and their gene expression. Curr Genet 31:380395.

eny using the mitochondrially encoded NAD5 protein sequence. Can J Bot 73(Suppl 1):S189-S195.

Patterson DJ. 1989. Stramenopiles: chromophytes from a protistan perspective. In: Green JP, Leadbeater BSC, Diver WC, eds. The chromophyte algae: problems and perspectives. Oxford, UK: Clarendon Press. p 357-379.

Powell MJ, Blackwell WH. 1995. Searching for homologous ultrastructural characters in zoosporic fungi. Can J Bot 73(Suppl 1):S693-S700.

Reischer HS. 1951a. Growth of Saprolegniaceae in synthetic media. I. Inorganic nutrition. Mycologia 43:142-155.

. 1951 b. Growth of Saprolegniaceae in synthetic me- 
dia. II. Nitrogen requirements and the role of Krebs cycle acids. Mycologia 43:319-328.

Sachay DJ, Hudspeth DSS, Nadler SN, Hudspeth MES. 1993. Oomycete mtDNA: Phytophthora genes for cytochrome $c$ oxidase use an unmodified genetic code and encode proteins most similar to plants. Exp Mycol 17: 7-23.

Shumard DS, Grossman LI, Hudspeth MES. 1986. Achlya mitochondrial DNA: gene localization and analysis of inverted repeats. Mol Gen Genet 202:16-23.

Shumard-Hudspeth DS, Hudspeth MES. 1990. Genic rearrangements in Phytophthora mitochondrial DNA. Curr Genet 17:413-415.

Sparrow FK. 1973. Lagenidiales. In: Ainsworth GD, Sparrow FK, Sussman AS, eds. The fungi. An advanced treatise. Vol. IVB. New York: Academic Press. p 159-163.

Swofford DL. 1993. PAUP: Phylogenetic analysis using parsimony, version 3.1.1. Champaign, Illinois: The Illinois Natural History Survey.

Tsukihara T, Aoyama H, Yamashita E, Tomizaki T, Yama- guchi H, Shinzawa-Itoh K, Nakashima R, Yaono R, Yoshikawa S. 1995. Structures of metal sites of oxidized bovine heart cytochrome $c$ oxidase at $2.8 \mathrm{~A}$. Science 269:1069-1074.

Van de Peer Y, Van der Auwera G, De Wachter R. 1996. The evolution of stramenopiles and alveolates as derived by "substitution rate calibration" of small ribosomal subunit RNA. J Mol Evol 42:201-210.

Van der Auwera G, De Baere R, Van de Peer Y, De Rijk P, Van den Broeck I, De Wachter R. 1995. The phylogeny of the Hyphochytriomycota as deduced from ribosomal RNA sequences of Hyphochytium catenoides. Mol Biol Evol 12:671-678.

Wolff G, Plante I, Lang BF, Kuck U, Burger G. 1994. Complete sequence of the mitochondrial DNA of the chlorophyte alga Prototheca wickerhamii. Gene content and genome organization. J Mol Biol 237:75-86.

Waterhouse GM. 1973. Peronosporales. In: Ainsworth GD, Sparrow FK, Sussman AS, eds. The fungi. An advanced treatise. Vol. IVB. New York: Academic Press. p 165183.

Note added in proof: While this manuscript was in review both SSU-rRNA (Dick et al, 1999. Mycol Res 103:1119-1125) and LSU-rRNA (Riethmuller et al, 1999. Can J Bot-Rev Can Bot 77:1790-1800) phylogenies appeared. 